\title{
Micromorfologia e mineralogia de unidades pedoestratigráficas coluviais em paleofundo de vale na superfície de São José Dos Ausentes (RS)
}

\author{
Micromorphology e mineralogy of colluvial pedoestratigraphics units in \\ paleovalley bottom on the surface of São José Dos Ausentes (RS)
}

\author{
Josielle Samara Pereira', Julio Cesar Paisan"
}

\section{RESUMO}

Este artigo exibe resultados da determinação micromorfológica e mineralógica de materiais coluviais em paleofundo de vale na superfície de São José dos Ausentes (RS). A análise micromorfológica teve por objetivo verificar paleoprocessos pedogenéticos dos materiais fontes de colúvios, processos sedimentares e transformações pós-deposicionais. Já a mineralogia foi realizada para verificar os produtos do intemperismo dos materiais fontes dos colúvios, possibilitando tecer considerações a respeito da área fonte, do grau de retrabalhamento do material e do estágio de evolução intempérica. A micromorfologia mostrou similaridade entre os horizontes coluviais, sugerindo assim, se tratarem de materiais oriundos na mesma fonte e fase pedogenética. O processo de sedimentação coluvial misturou níveis pedológicos da área fonte com diferentes graus de pedogênese/intemperismo, data a presença de fragmentos líticos e nodulações, dentre outras microfeições. A descrição mineralógica mostrou que há presença de minerais primários relativamente resistentes ao intemperismo, juntamente com minerais menos resistentes ao intemperismo, sugerindo assim como hipótese três situações da dinâmica entre pedogênese e morfogênese na área fonte dos sedimentos: o material fonte deriva de solo pouco evoluído do ponto de vista pedogeoquímico, ou houve contínua remoção até os níveis do saprolito, ou ambas as situações.

\section{Palavras-chave: Colúvio; Quaternário; Significado paleoambiental}

\section{ABSTRACT}

A colluvial of paleovalley bottom, located on the surface of São José dos Ausentes (RS). The micromorphological analysis aimed to verify the pedogenic paleoprocesses of colluviums materials sources, sedimentary processes and post-depositional transformations. The minerology were performed to verify the weathering products of colluviums materials sources, enabling to build consideration about the source area, degree of material reworking and the weathering evolution stage of the material. The micromorphology showed similarities between colluvial horizons, indicating materials from the same pedogenetic source and phase. The colluvial sedimentation process blended pedological levels of the source area with different degrees of pedogenesis/weathering, being present lithic fragments and nodulation, among others micro-feature. The mineralogical description, showed the presence of primary minerals relatively resistant to weathering, as well as with less resistant minerals to weathering, proposing as hypothesis, three situations of the dynamic between

'Doutoranda do programa de Pós-Graduação em Geografia - Mestrado e Doutorado da UNIOESTE - Francisco Beltrão" Filiação institucional de autoria. E-mail. josy.samara@hotmail.com ORCID https://orcid.org/0000-0002-4309-1833

"Docente do curso de Geografia e do programa de Pós-Graduação em Geografia - Mestrado e Doutorado da UNIOESTE - Francisco BeltrãoE-mail. uliopaisani@hotmail.com ORCID https://orcid.org/0000-0002-8911-6477 
pedogenesis and morphogenesis in the source area of the sediments: source material derived from soil poorly developed in pedogeochemical terms, or there was continuous removal until the saprolite levels, or both situation.

Keywords: Colluvium; quaternary; paleoenvironmental meaning

\section{INTRODUÇÃO}

O estudo referente à análise pedoestratigráfica tem sido cada vez mais importante para a compreensão evolutiva da paisagem, permitindo entender a dinâmica relacionada à gênese e a evolução das diferentes formas de relevo (SUGUIO, 1999). Nos últimos 50 anos, os estudos geomorfológicos no Brasil tiveram grande expansão, objetivando compreender os eventos ocorridos ao longo do período Quaternário.

No caso especificamente da região Sul do Brasil, algumas pesquisas estão sendo realizadas nos Estados de Santa Catarina (SC) e do Paraná (PR) pelo grupo de pesquisa Gênese e Evolução de Superfícies Geomórficas e Formações Superficiais (GESGFS) formado na Universidade Estadual do oeste do Paraná (UNIOESTE). O referido grupo de pesquisa vem desenvolvendo pesquisas a respeito da evolução da paisagem em área de ocorrência dos derrames vulcânicos da bacia do Paraná no Sul do Brasil. Até o momento foram gerados resultados para o entendimento da paisagem no Sudoeste (SW) do Paraná e Noroeste (NW) de Santa Catarina, área conhecida como Planalto das Araucárias (ALMEIDA, 1956).

Ao longo desta região identificaram-se oito remanescentes de superfícies aplainadas (PAISANI et al., 2008). Em rebordos de patamares desses remanescentes de superfícies verificam-se formações superficiais alóctones como depósitos de colúvio, alúvio, colúvioalúvio e paleossolos, cujos registros ambientais estratigráficos foram capazes de trazer melhor compreensão a respeito da gênese e evolução da paisagem quaternária para esta região (PAISANI et al., 2008; PAISANI e PONTELLI, 2010, 2012; PAISANI et al., 2015, 2017).

Correspondente a ocorrência dos derrames vulcânicos da Bacia do Paraná no Rio Grande do Sul, poucos são os estudos referentes ao Quaternário Continental nesta região. Portanto, objetivou-se estudar essa região afim de não somente contribuir para os estudos paleoambientais do Sul do Brasil como também buscar indícios compatíveis aos fenômenos verificados no Sudoeste (SW) do Paraná e Noroeste (NW) de Santa Catarina. 
Assim, uma alternativa para compreensão do relevo é através do estudo relacionado ao grau de evolução pedológica dos materiais fontes dos registros estratigráficos. Assim, pode-se recorrer a micromorfologia e a determinação mineralógica dos materiais estratigráficos. A micromorfologia é uma análise que permite identificar as relações litológicas e pedológicas entre os materiais, assim como os processos e mecanismos associados, trazendo informações a respeito da dinâmica genética e evolutiva dos materiais (STOOPS, 2003). Em relação à mineralogia esta se define por ser a mais importante ferramenta para o estudo dos minerais do solo (RESENDE et al., 2005), e é utilizada para verificar os produtos relacionado ao intemperismo dos materiais.

Neste sentido, o presente artigo traz resultados referente a determinação micromorfológica e mineralógica de unidades pedoestratigráficas coluviais em paleofundo de vale de segunda ordem hierárquica localizada na superfície de São José dos Ausentes (RS). A primeira determinação objetiva verificar paleoprocessos pedogenéticos dos materiais fontes de colúvios, processos sedimentares e transformações pós-deposicionais e a segunda verificar os produtos do intemperismo dos materiais fontes dos colúvios, tecer considerações a respeito da área fonte, do grau de retrabalhamento do material e do estágio de evolução intempérica. Tais resultados visam compreender a dinâmica genética e evolutiva dos materiais, contribuindo assim aos estudos paleoambientais do Sul do Brasil, mais especificamente na região Nordeste do Estado do Rio Grande do Sul.

\section{2 ÁREA DE ESTUDO}

A área de estudo se localiza na região Sul do Brasil, mais especificamente no Nordeste do Estado do Rio Grande do Sul (Figura 1). O paleofundo de vale estudado é drenagem remanescente de segunda ordem hierárquica da bacia hidrográfica do rio dos Touros, colmatada durante o Quaternário Tardio. Ele se encontra na Superfície de São José dos Ausentes entre 1.100 a $1.200 \mathrm{~m}$ de altitude (PEREIRA et al., 2016), e foi identificado com base em seção estratigráfica evidenciada em corte de estrada da BR 285 (Figura 1). A Superfície de São José dos Ausentes é um compartimento do Planalto basáltico da Bacia do Paraná, também conhecido como Planalto das Araucárias (ALMEIDA, 1956; ROSS, 2011), mantido 
por rochas vulcânicas da Formação Serra Geral, Fácies Caxias, do Neocretáceo (WILDNER et al., 2006).

Figura 1 - Localização da área de estudo.

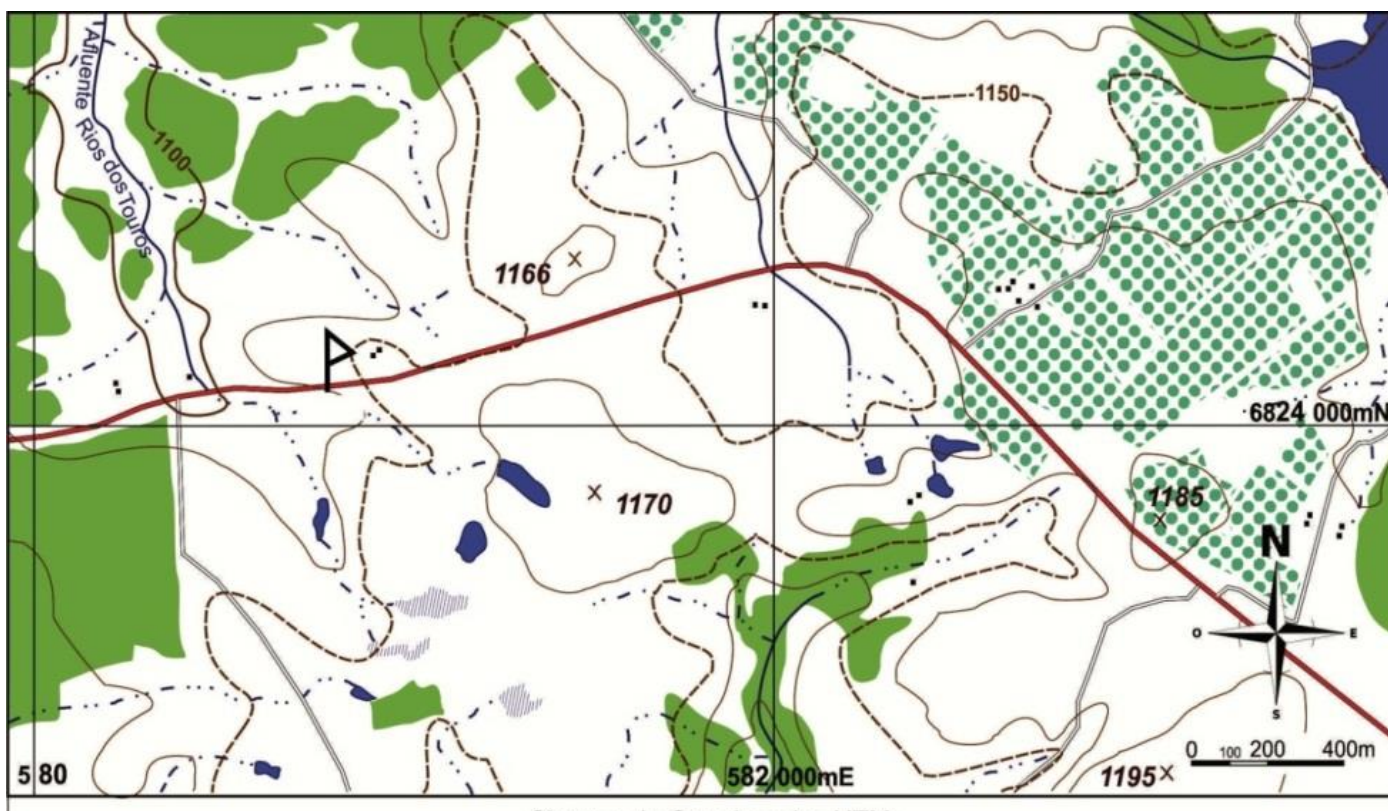

Sistema de Coordenadas UTM:

Datum horizontal - Córrego Alegre/MG; Datum Vertical - Mareógrafo de Torres/RS

Legenda

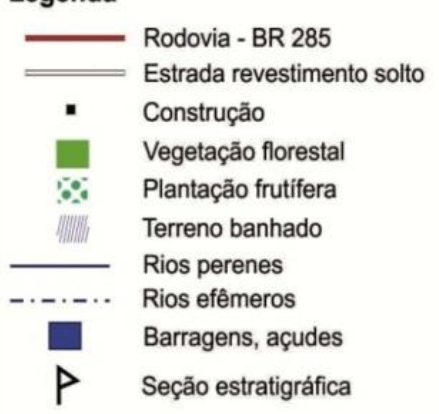
Equidistância das curvas de nivel - 20 metros

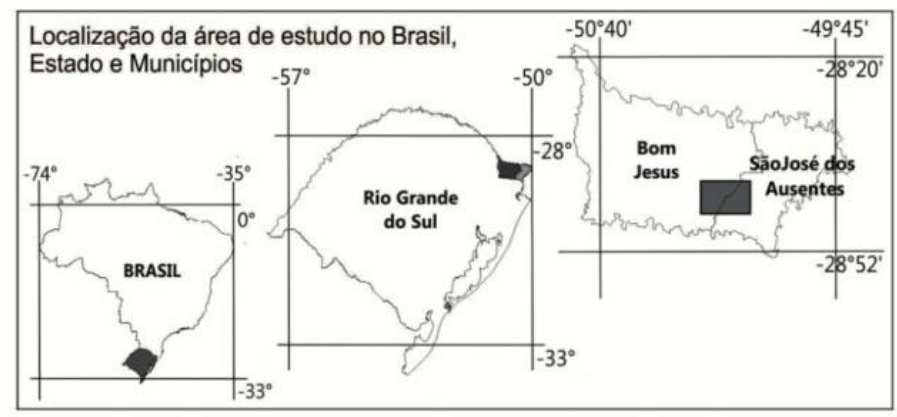

Fonte dos dados: IBGE - Banco de Dados Spring Atlas_2008 - Carta Topográfica DSG (MI: 2938-2) SH-22-X-A-V-2 - Escala: 1/50.000

Fonte: Organização dos autores.

O relevo se apresenta suave-ondulado a ondulado (SCHLICK, 2004), o solo é classificado como Cambissolos Húmicos Distrófico e Neossolos Litólicos Eutrófico e Órtico (IBGE - EMBRAPA, 2001). Já a vegetação se classifica como Floresta Ombrófila Mista (com Araucárias) e Estepe (campos do sul do Brasil) (IBGE, 2004), com manchas de Florestas de Araucária (SCHERER e LORSCHEITTER, 2014). O Clima regional é classificado como Cfb (C: clima mesotérmico temperado; f: Clima úmido, com chuva bem distribuída durante o ano todo; b: verão temperado) (KUINCHTNER e BURIOL, 2001). 


\section{MATERIAIS E MÉTODOS}

A seção estratigráfica, designada de SJA1 (São Jose dos Ausentes 1), tem aproximadamente $30,70 \mathrm{~m}$ de comprimento e $6 \mathrm{~m}$ de altura. Seus materiais foram descritos levando em consideração o uso conjunto de critérios lito-, pedo-, alo- e crono-estratigráfico (PEREIRA, 2017). O critério litoestratigráfico foi utilizado para identificar as unidades coluviais. A pedoestratigrafia possibilitou identificar a atuação da pedogênese e balizou a nomenclatura final dos níveis estratigráficos, haja vista presença de paleossolo enterrado (níveis 24 a 27). A aloestratigrafia identificou as descontinuidades mais marcantes dos registros estratigráficos. Já, o critério cronoestratigráfico buscou entender as fases cronológicas dos eventos de pedogênese e morfogênese. A síntese dos materiais da seção está exposta em seção colunar composta, e é constituída por três sequencias de solos coluviais sobrepostos a paleossolo hidromorfico enterrado (Figura 2). 
6 | Micromorfologia E Mineralogia De Unidades Pedoestratigráficas Coluviais Em Paleofundo De Vale Na Superfície De São José Dos Ausentes (RS)

Figura 2 - Seção colunar pedoestratigráfica balizada pela cronoestratigrafia e fácies do substrato. Nomenclatura textural baseada em Ghibaudo (1992).

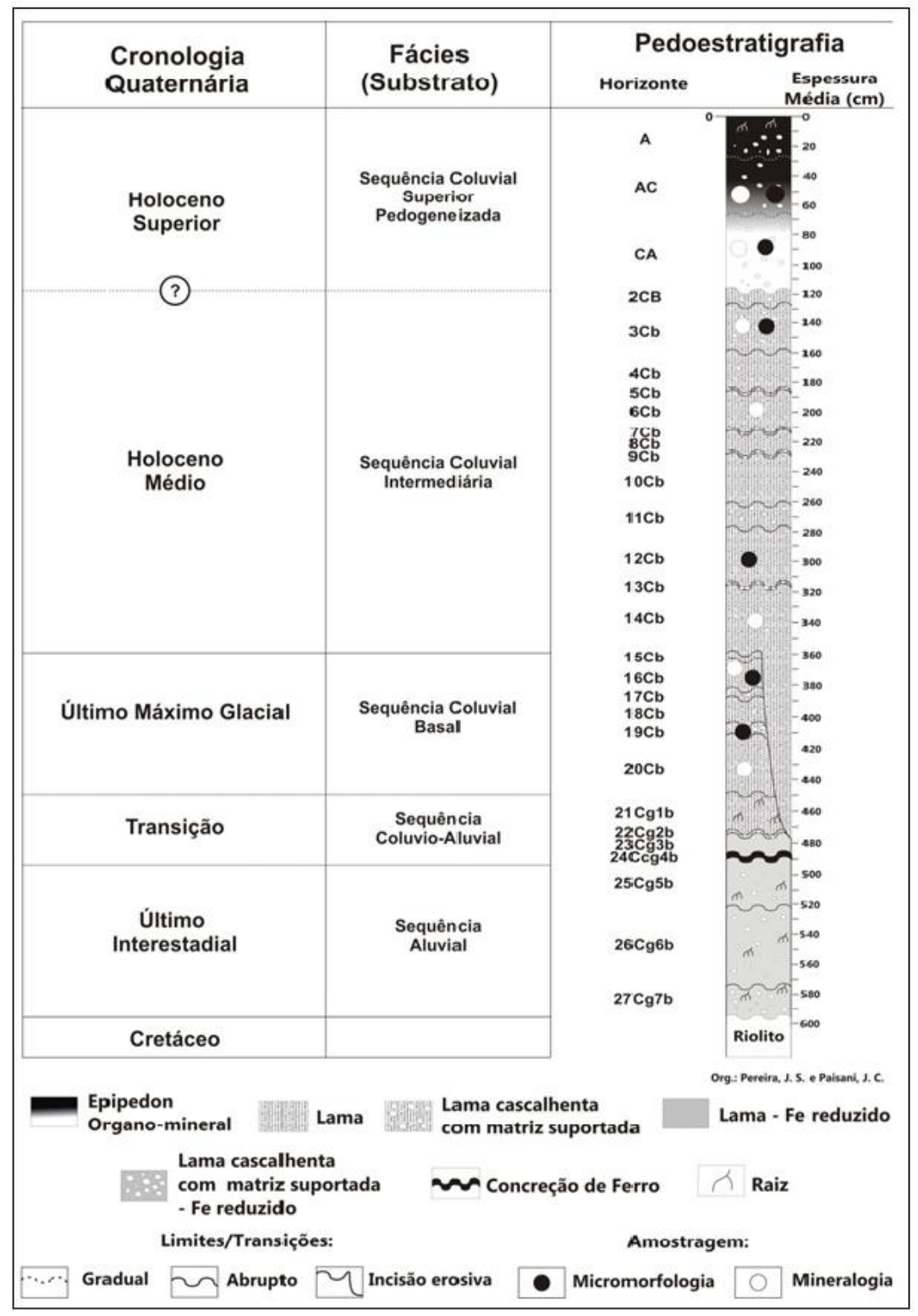

Fonte: Adaptado de Pereira, 2017.

As sequencias coluviais foram geradas entre o Último Máximo Glacial e o Holoceno Médio, havendo hiato erosivo durante o Holoceno Inferior, como evidência incisão erosiva (Paleovoçoroca) (Figura 2). Foram reconhecidos 30 horizontes ao longo dessas sequências, dos quais 3 são classificados como materiais resultantes da pedogênese moderna (sequência coluvial superior pedogeneizada), individualizados como horizontes $A, A C$ e CA, 13 horizontes definidos como material coluvial presentes na sequência coluvial intermediária, sendo eles: $2 \mathrm{Cb}, 3 \mathrm{Cb}, 4 \mathrm{Cb}, 5 \mathrm{Cb}, 6 \mathrm{Cb}, 7 \mathrm{Cb}, 8 \mathrm{Cb}, 9 \mathrm{Cb}, 10 \mathrm{Cb}, 11 \mathrm{Cb}, 12 \mathrm{Cb}, 13 \mathrm{Cb}$, 
$14 \mathrm{Cb}$, e sete deles compondo a sequência coluvial basal: $15 \mathrm{Cb}, 16 \mathrm{Cb}, 17 \mathrm{Cb}, 18 \mathrm{Cb}, 19 \mathrm{Cb}$ e 20Cb, 21Cg1b. Por fim, os outros seis níveis estratigráficos constituem o paleossolo hidromorfico flúvico, sendo individualizados como horizontes $22 \mathrm{Cg} 2 \mathrm{~b}, 23 \mathrm{Cg} 3 \mathrm{~b}, 24 \mathrm{Ccg} 4 \mathrm{~b}$, 25Cg5b, 26Cg6b e 27RCg7; além da alterita de riolito constituindo o horizonte 28RCg7.

A análise micromorfológica foi realizada para verificar paleoprocessos pedogenéticos dos materiais fontes de colúvios, processos sedimentares e transformações pósdeposicionais geradas pela retomada da pedogênese, conforme recomendado por Paisani e Pontelli (2012). Esta técnica foi realizada em seis amostras indeformadas, dos níveis pedoestratigráficos: $\mathrm{AC}, \mathrm{CA}, 3 \mathrm{Cb}, 12 \mathrm{Cb}, 16 \mathrm{Cb}$ e $19 \mathrm{Cb}$ da seção estratigráfica (Figura 2). As amostras foram impregnadas e laminadas por meio dos serviços do Laboratório de Laminação da USP (SP). As descrições das lâminas foram realizadas no Laboratório de Microscopia Ótica (Micromorfologia) da Universidade Estadual do Oeste do Paraná, campus Francisco Beltrão, baseando-se nos critérios e terminologias propostas por Stoops (2003).

A mineralogia das frações areia, silte e argila foi realizada para verificar os produtos do intemperismo dos materiais fontes dos colúvios responsáveis pelos horizontes representativos dos principais níveis estratigráficos das sequências coluviais: $A C, C A, 3 C b$, $6 \mathrm{Cb}, 14 \mathrm{Cb}, 16 \mathrm{Cb}$ e $20 \mathrm{Cb}$ (Figura 2). As amostras foram preparadas no Laboratório de Análises e Formações Superficiais da Universidade Estadual do Oeste do Paraná, campus de Francisco Beltrão, e encaminhadas para Laboratório de Mineralogia da Universidade Federal de Viçosa. O laboratório utiliza-se do difratômetro de raio-X marca Panalytical, modelo X pert Pro, em exemplares desferrificados (ditionito-citrato) e orientados com tratamento de aquecimento (temperatura ambiente, $350^{\circ} \mathrm{C}$ e $550^{\circ} \mathrm{C}$ ) e saturação com K, Mg e etilenoglicol. Os difratogramas foram confeccionados utilizando-se o software Phillips X'Pert HighScore e interpretados, em gabinete na UNIOESTE, seguindo o quadro de padrões apresentados por Brindley e Brow (1980, apud RESENDE et al. 2005), bem como os pressupostos de Resende et al. (2005). 


\section{MATERIAIS E MÉTODOS}

\subsection{Micromorfologia das fácies coluviais}

Os principais atributos micromorfológicos dos horizontes $\mathrm{AC}, \mathrm{CA}, 3 \mathrm{Cb}, 16 \mathrm{Cb}, 12 \mathrm{Cb}$ e $19 \mathrm{Cb}$ estão demostradas na Tabela 1. O horizonte $19 \mathrm{Cb}$ corresponde a linha de pedras envolvida por matriz, cuja fração grossa é constituída, predominantemente, de quartzo nas frações areia muito fina a areia grossa. Registra-se também a ocorrência, porém em menor proporção de ilmenita/magnetita, nódulos mátricos intrusivos e intercalação concentrando óxido de $\mathrm{Fe} / \mathrm{Mg}$, lito- e alterorrelíqueas.

Tabela 1 - Atributos micromorfológicos dos horizontes AC, CA, 3Cb, 12Cb, 16Cb e 19Cb. ${ }^{\mathrm{a}} \mathrm{Qz}=$ quartzo, $\mathrm{Fr}=$ fragmento de rocha, $\mathrm{Li}=$ =litorrelíquea/alterorrelíquia, $\mathrm{Pe}=$ pedorrelíquea, $\mathrm{Np}=$ nódulo pedomórfico reliquitual, I/M=ilmenita/magnetita. ${ }^{1}<20 \%,{ }^{2}<50 \%,{ }^{3} \geq 50 \%$, ${ }^{b}$ amf=areia muito fina, $a f=$ areia fina, am=areia media, ag=areia grossa, ${ }^{c}$ ba $=$ bruno amarelado (10YR 5/8- Munsell Chart), be=bruno amarelado escuro (10YR 4/6 - Munsell Chart), bae=bruno acinzentado muito escuro (10.YR 3/2), - Munsell Chart), din=indiferenciada, $m=$ cristalítica manchada/pontilhada, esp= cristalítica estriada/paralela, esg = cristalítica granoestriada e pa=porfírica aberta, pf=porfírica fechada espaço duplo,

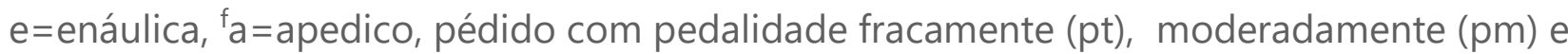
fortemente $(\mathrm{pf})$ desenvolvida, ${ }^{9} \mathrm{Cv}=$ cavitário, c=canal/câmara, $\mathrm{p}=$ planar, hhci=hiporevestimento de impregnação, hcd=hiporevestimento de depleção, qci=quaserevestimento de impregnação, qcd=quaserevestimento de depleção, ntf=nódulo típico, nnf=nódulo nucleico, associação com matriz ${ }^{4}$, poro ${ }^{5}$, grão ${ }^{6}, b=$ pedobioturbação, gl=grãos da fração grossa dispostos de forma circular (galácticos).

\begin{tabular}{|c|c|c|c|c|c|c|c|c|}
\hline \multicolumn{3}{|c|}{ Material Grosso } & \multicolumn{2}{|c|}{ Micromassa } & \multirow[b]{2}{*}{$\begin{array}{l}\text { Distribui } \\
\text { ção } \\
\text { Relativa } \\
\text { e }\end{array}$} & \multirow[b]{2}{*}{$\begin{array}{l}\text { Pedalid } \\
\text { ade }^{f}\end{array}$} & \multirow[b]{2}{*}{ Poros } & \multirow[b]{2}{*}{$\underset{h}{\text { Pedofeições }}$} \\
\hline $\begin{array}{l}\text { Horizonte } \\
\text { / } \\
\text { Profundid } \\
\text { ade }(\mathrm{cm})\end{array}$ & $\begin{array}{l}\text { Composiç } \\
\text { ão }^{\mathrm{a}}\end{array}$ & $\begin{array}{c}\text { Tamanho } \\
\text { Predomina } \\
\text { nte }^{b}\end{array}$ & $\underset{c}{\text { Cor }}$ & $\begin{array}{c}\text { Fábric } \\
\text { a } \\
\text { Matriz }^{d}\end{array}$ & & & & \\
\hline
\end{tabular}




\begin{tabular}{|c|c|c|c|c|c|c|c|c|}
\hline$A C$ & $\begin{array}{l}\mathrm{Qz}^{3}, \mathrm{I} / \mathrm{M}^{2} \\
\mathrm{~Np}^{1}, \mathrm{Pe}^{1}\end{array}$ & $\begin{array}{c}a m f^{2}, a^{2}, \\
a m^{2}\end{array}$ & bae & $\mathrm{I}^{3}, \mathrm{~m}^{2}$ & $\mathrm{pa}^{3}$ & $\mathrm{pm}^{3}, \mathrm{a}^{1}$ & $\mathrm{p}^{3}, \mathrm{cv}^{2}$ & $\begin{array}{l}\mathrm{hci}^{25}{ }^{6}, \mathrm{~b}^{1} \\
\mathrm{nt}^{1}, \mathrm{nn}^{1}, \mathrm{gl}\end{array}$ \\
\hline CA & $\begin{array}{l}\mathrm{Qz}^{3}, \mathrm{I} / \mathrm{M}^{2} \\
\mathrm{~Np}^{1}, \mathrm{Pe}^{1}\end{array}$ & $\begin{array}{c}\mathrm{amf}^{2}, \mathrm{af}^{2} \\
\mathrm{am}^{3}\end{array}$ & $b e^{3}$ & $\begin{array}{c}\mathrm{m}^{3}, \mathrm{i}^{1} \\
\mathrm{es}^{1}\end{array}$ & $\mathrm{pa}^{3}$ & $a^{3}, p t^{1}$ & $\mathrm{p}^{3}, \mathrm{cv}^{2}$ & $\mathrm{hcd}^{2}, \mathrm{nt}^{2}, \mathrm{gl}$ \\
\hline $3 \mathrm{Cb}$ & $\begin{array}{c}\mathrm{Qz}^{3}, \mathrm{l} / \mathrm{M}^{2} \\
\mathrm{~Np}^{2}, \mathrm{Li}^{1} \\
\mathrm{Pe}^{2}\end{array}$ & $\begin{array}{l}\mathrm{amf}^{2}, \mathrm{af}^{2}, \\
\mathrm{am}^{2}, \mathrm{ag}^{1}\end{array}$ & $b^{3}$ & $\mathrm{~m}^{3}$ & $\mathrm{pa}^{3}, \mathrm{pf}^{1}$ & $a^{3}, p t^{1}$ & $c v^{3}, p^{2}$ & $\begin{array}{l}\mathrm{hci}^{25}, \mathrm{~b}^{1} \\
\mathrm{nt}^{2}, \mathrm{nn}^{1}, \mathrm{gl}\end{array}$ \\
\hline $12 \mathrm{Cb}$ & $\begin{array}{c}\mathrm{Qz}^{3}, \mathrm{Fr} \\
\mathrm{l} / \mathrm{M}^{2}, \mathrm{~Np}^{2} \\
\mathrm{Pe}^{2}\end{array}$ & $\begin{array}{l}\mathrm{amf}^{2}, \mathrm{af}^{2}, \\
\mathrm{am}^{1}, \mathrm{ag}^{2}\end{array}$ & $b^{3}$ & $\begin{array}{l}\mathrm{m}^{3} \\
\mathrm{esg}^{1}\end{array}$ & $\mathrm{pa}^{3}, \mathrm{e}^{1}$ & $\mathrm{pm}^{3}, \mathrm{a}^{2}$ & $c v^{3}, p^{1}$ & $n t^{2}, b^{1}$ \\
\hline $16 \mathrm{Cb}$ & $\begin{array}{c}\mathrm{Qz}^{3}, \mathrm{Fr}^{1} \\
\mathrm{I} / \mathrm{M}^{2}, \mathrm{~Np}^{2} \\
\mathrm{Pe}^{2}\end{array}$ & $\begin{array}{l}\mathrm{amf}^{2}, \mathrm{af}^{2}, \\
\mathrm{am}^{1}, \mathrm{ag}^{2}\end{array}$ & $b^{3}$ & $\begin{array}{l}\mathrm{m}^{3} \\
\mathrm{esg}^{1}\end{array}$ & $p a^{3}, \mathrm{pf}^{1}$ & $a^{3}, p t^{1}$ & $c v^{3}, p^{1}$ & $\begin{array}{l}\mathrm{hci}^{16}, \mathrm{hcd}^{25} \\
6, \mathrm{nt}^{2}, \mathrm{nn}^{1}, \mathrm{gl}\end{array}$ \\
\hline $19 \mathrm{Cb}$ & $\begin{array}{l}\mathrm{Qz}^{3}, \mathrm{Fr}^{1} \\
\mathrm{I} / \mathrm{M}^{2}, \mathrm{~Np}^{2} \\
\mathrm{Pe}^{2}, \mathrm{Li}^{1}\end{array}$ & $\begin{array}{l}\mathrm{amf}^{2}, \mathrm{af}^{2}, \\
\mathrm{am}^{1}, \mathrm{ag}^{2}\end{array}$ & $\mathrm{ba}^{3}$ & $\begin{array}{l}\mathrm{m}^{3} \\
\mathrm{esp}^{2} \\
\mathrm{in}^{2}\end{array}$ & $\begin{array}{c}\mathrm{pa}^{3}, \mathrm{pf}^{1} \\
\mathrm{e}^{1}\end{array}$ & $a^{3}, p m^{2}$ & $\begin{array}{c}\mathrm{Cv}^{3}, \mathrm{p}^{1} \\
\mathrm{c}^{1}\end{array}$ & $\begin{array}{l}\mathrm{hcd}^{2}, \mathrm{qci}^{1}, \\
\mathrm{nt}^{2}, \mathrm{nn}^{1}, \mathrm{gl}\end{array}$ \\
\hline
\end{tabular}

Fonte: Organização dos autores.

Os nódulos mátricos não mostram herança genética com o fundo matricial, o que lhes confere a gênese associada ao material fonte do colúvio. A distribuição relativa dos constituintes (DRC) predominante é porfírica aberta, mas localmente ocorre profírica fechada singular, cujos grãos da fração grossa expressam organização lenticular, e localmente enáulica (Figura 3A). Poros caviários poligonais são predominantes, porém registra-se planares e canais.

Figura 3 - Micrografias dos horizontes AC (H), CA (G), 3Cb (F), 12Cb (E), 16Cb (D) e 19Cb (A, B e C). A - Organização bandada pela orientação alinahada da fração areia grossa; B Pedorrelíquea de agregado com cor laranja; C - Pedorrelíquea tipo intercação; D Pedorrelíquea como hiporevestimento de impregnação de grão; E - Pedorrelíquea de agregado e desmantelamento do material separado pelos poros na matriz; F Bandeamentos; G - Nódulo núcleico típico; H - Melanização do material e grãos dispostos de forma circular (galáticos). 

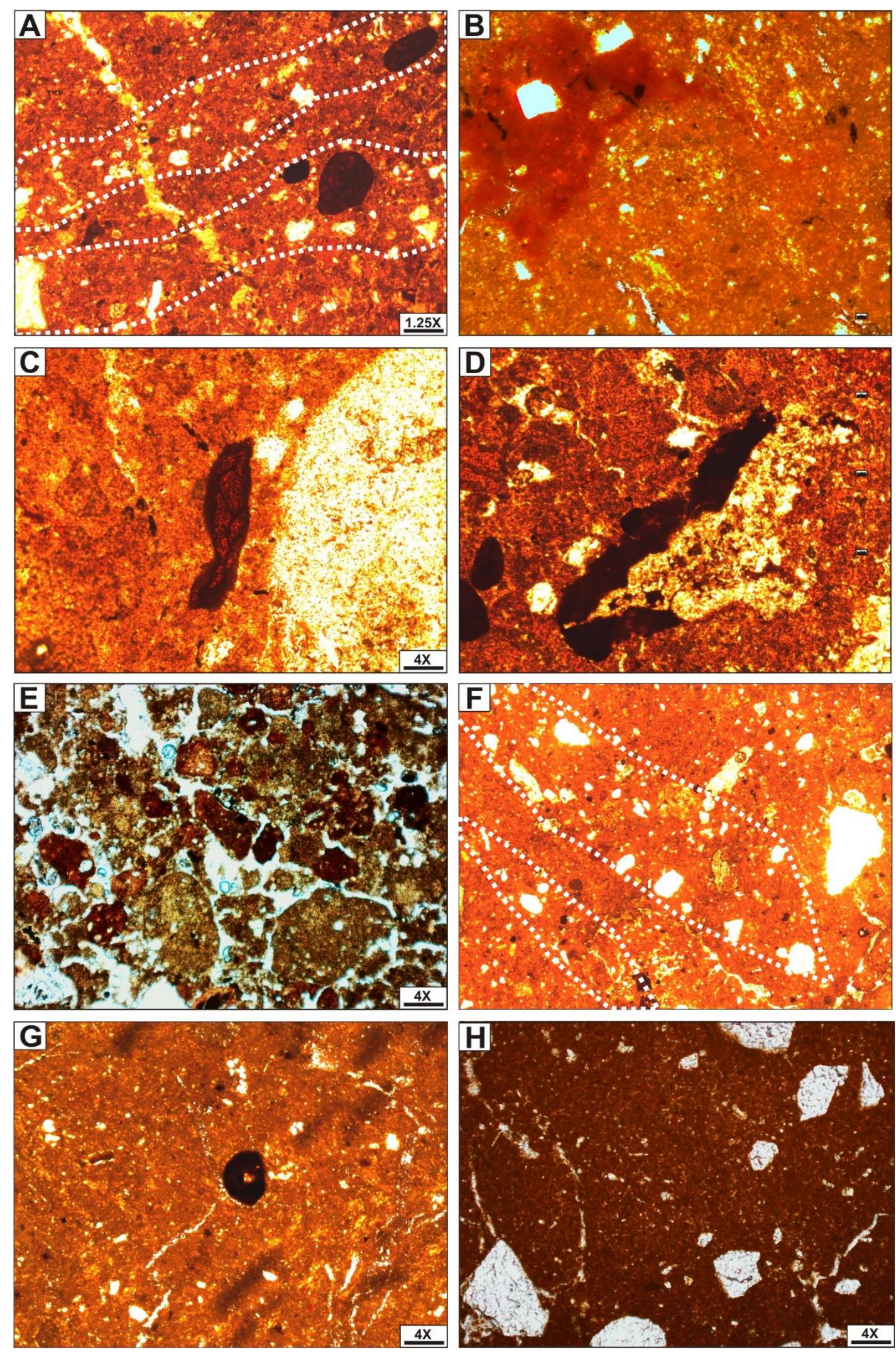

Fonte: Organização dos autores.

A micromassa é composta por dois materiais distintos, um de cor bruno amarelado e outro laranjado que não expressam continuidade lateral. Esses materiais correspondem a agregados de materiais distintos suturados após a sedimentação (coalescentes) (BIFFI e 
PAISANI, 2019), cujos limites são nítidos e correspondem a pedorreliquías tipo agregado (Figura 3B). Eles apresentam orientação predominante cristalítica manchada/pontilhada a paralela estriada descontínua, variando de agregado para agregado.

Vinculado aos poros destaca-se a presença de hiporevestimentos de depleção e quaserevestimento de impregnação. Observa-se a dispersão de argila resultante da quebra da ligação Fe/Argila na matriz antes do estabelecimento de poros planares, como se pode verificar os preenchimentos descontínuos límpidos em alguns poros dessa categoria (material amarelo) (Figura 3A). Isso, possivelmente, esteja relacionado a periodicidade de saturação/dissecação com depleção de Fe, Mn e Argila (SCHAETZL e ANDERSON, 2005). Não se registra nódulos pedomórficos gerados na matriz por concentração de Fe, enquanto que nódulos com forte impregnação são pedorrelíquias da área fonte (Figura 3C). Parece que quebra das ligações na matriz é um processo recorrente tanto na área fonte quanto no material sedimentado, em face dos hipo- e quaserevestimentos. De todo modo, os nódulos relíquituais sugerem que o solo da área fonte passou por múltiplos ciclos de saturação/dissecação (condições de redox) antes de ser remobilizado e sedimentado no fundo do vale de baixa ordem.

No geral, o material, por apresentar predomínio da matriz porfírica aberta e localmente fechada singular leva a pensar em fluxos rasos de lama ou escoamento superficial com diferentes concentrações de sedimentos no fluxo (BERTRAN e TEXIER, 1999; ARAÚJO et al., 2017). Além desses mecanismos de sedimentação, inclui-se como possibilidade deformações pós-deposicionais decorrentes da compactação devido a presença de agregados suturados (coalescentes) com diferentes constituições (FEDOROFF et al. 2010). A sutil pedalidade sugere que a unidade poderia ser mais espessa com estabelecimento de superfície topográfica em seu topo. Por outro lado, sua característica em macroescala de linha de pedras não apresenta coerência com o registro micromorfológico, acarretando em recorrente truncamento erosivo pós-deposicional.

O horizonte $16 \mathrm{Cb}$ compreende nível delgado relativamente homogêneo devido ao predomínio de matriz em relação à fração grossa. A fração grossa é similar ao horizonte 19Cb, porém, registram-se menor quantidade de bandeamentos vinculados a fração grossa no material do horizonte $19 \mathrm{Cb}$, porém são comuns grãos de quartzo dispostos de forma 
circular (galácticos - MÜCHER et al.,2010). Identificou-se a ocorrência de maior concentração de pedorrelíquea de agregados. Sua matriz, manchada de diferentes tons de laranja, sugere nível pedológico da área fonte em que as condições de oxidação prevaleciam em relação às de redução. Por outro lado, a presença de nódulo com forte impregnação em uma das pedorrelíquias "laranjas" atesta longa fase de condições de redoximórficas. Assim, pode-se pensar em material da área fonte derivado de nível pedológico similar ao horizonte B de um solo moderno moderamente bem drenado a bem drenado, cujo lençol freático poderia estar à aproximadamente $100 \mathrm{~cm}$ de profundidade.

O material se apresenta apédico, sendo localmente pédico. Foi observado pedorrelíquea como hiporevestimento de impregnação vinculado a grãos (Figura 3D), tratase de uma pedorrelíquia do solo da área fonte atualmente envolvido na matriz do atual nível 16Cb. Esta impregnação no grão parece estar relacionado a movimentação da água de forma recorrente e prolongada a partir da saturação de uma frente de umidade capilar próxima do lençol freático ou próxima de uma descontinuidade hidráulica (horizonte de impedimento aos fluxos verticais de água).

Contudo, soma-se o fato do material da matriz do horizonte $16 \mathrm{Cb}$ ser similar ao $19 \mathrm{Cb}$, sugerindo que se trata da mesma fonte de material. Tal fato leva a pensar que na área fonte ainda predominava a pedogênese regressiva (desmantelamento do solo pela erosão na conceituação de JOHNSON et al., 1990). As microfeições trouxeram a informação de que a migração do Fe era comum no material, confirmando a ideia assim como no horizonte $19 \mathrm{Cb}$, de um regime hídrico com duas estações bem definidas. No geral, o material porfírico com pedalidade ausente a fraca, grãos da fração grossa dispostos como galáticos sugere que o colúvio foi gerado por fluxo com comportamento plástico, possivelmente fluxo de lama raso ou escoamento superficial com alta concentração de sedimentos, similarmente a gênese do horizonte $19 \mathrm{Cb}$.

O horizonte $12 \mathrm{Cb}$ registra homogeneidade morfológica. A constituição da fração grossa, em geral, não se difere das características dos horizontes 19Cb e 16Cb. Os nódulos são mátricos, porém, assim como nos demais horizontes, não apresentam relações genéticas com a matriz envolvente, configurando como pedorrelíquias da área fonte. Nesse horizonte observaram-se fragmentos líticos com alterosplasmação (DELVIGNE, 1998) e a presença de 
microartefatos (ARAÚJO et al. 2017). Não se identificou bandeamentos vinculados a fração grossa, apenas maior individualização dos agregados constituindo distribuição relativa localmente enáulica. Em relação à micromassa, a matriz tem orientação manchada/pontilhada, e localmente granoestriada. Esta última aponta a depleção como processo que também atuou na fase de sedimentação (sindeposiconal), similarmente ao verificado no horizonte $19 \mathrm{Cb}$. As pedorrelíqueas se apresentaram em maior quantidade e variedade em relação às identificadas nos horizontes $19 \mathrm{Cb}$ e $16 \mathrm{Cb}$, individualizadas como pedorrelíqueas de agregado (Figura 3E).

O material do horizonte $12 \mathrm{Cb}$ se mostrou mais fragmentado (enáulica) em relação aos horizontes $19 \mathrm{Cb}$ e $16 \mathrm{Cb}$, onde se observa localmente o desmantelamento do material e a individualização de agregados sendo separados pelos poros na matriz (Figura 3E). Essa individualização pode indicar compactação parcial de material granular ou separação de material granular por ação biogênica. Nesse último caso indicaria que o material esteve mais próximo a uma paleosuperfície, onde também se observa que as laminações estão sendo desmanteladas. Foi possível identificar ausência de depleção em condições pósdeposicional no material, e que de fato a matriz guarda a depleção devido ao processo sindeposicional (STOLT e LINDBO, 2010).

O horizonte $3 \mathrm{Cb}$ corresponde ao último horizonte localizado na parte superior da sequência coluvial intermediária. A fração grossa se apresenta similar aos outros horizontes. Observam-se bandeamentos constituidas pela fração grossa (Figura 3F) e, localmente, grãos de quartzo dispostos de forma circular. Em relação à fração fina localmente, ocorrem hiporevestimentos de impregnação em poros planares, apresentando raras pedobioturbações e hiporevestimentos de depleção de grão. Há menor quantidade de nódulos que nos horizontes anteriores.

Seu material exibe ausência de pedalidade. Os constituintes do material do horizonte $3 \mathrm{Cb}$ é similar ao horizonte $16 \mathrm{Cb}$, assim pode-se evidenciar que entre esses dois horizontes de fato se estabeleceu uma paleosuperfície onde se depositou acima o material do horizonte 3Cb. Sua matriz se mostra passando por condições de redox com a depleção moderna de Fe, junto a microporos e contato entre matriz e fração grossa, como evidenciam os hipocurevestimentos de depleção de grão. Essas são microfeições que mostram a 
recorrência de processos já identificados na área fonte e que respondem as condições de umidade e temperatura modernas.

No material do horizonte CA a fração grossa não se diferencia dos horizontes descritos anteriormente. Os nódulos se apresentam em menor quantidade, sendo classificados como típicos, com destaque a ocorrência rara de nucleico (Figura 3G). Assim como no horizonte $12 \mathrm{Cb}$ não foram identificadas bandeamentos, porém, localmehte ocorrem grãos de quartzo dispostos de forma circular.

A micromassa se apresenta com cor mais escura em relação ao material dos horizontes mencionados anteriormente (Figura 3G), com orientação manchada, localmente indiferenciada e estriada. A orientação estriada denota tanto processos deformacionais pósdeposicional quanto a ação incipiente de processos pós-deposicionais vinculados a pedogênese durante o Quaternário Superior. Observa-se menor quantidade de pedorrelíqueas e a presença de hiporevestimento de depleção no material. Em relação aos poros, verificou-se o predomínio de poros planares seguidamente de cavitários, fato esse que se diferencia dos outros horizontes descritos anteriormente e pode indicar maior sazonalidade hídrica pós-deposicional.

O material do horizonte AC demonstra DRC porfírica aberta, cuja fração grossa apresenta maior quantidade de quartzo e presença de alterorrelíqueas. Localmente os grãos de quartzo estão dispostos de forma circular (Figura 3H). Os nódulos se mostram como típico e localmente verificaram-se alguns nucléicos. Estes correspondem a pedorrelíquias da área fonte, e são indicativos de múltiplos ciclos de condições de redox pelo qual o material fonte passou (LINDBO et al., 2010).

Na fração fina, observou-se melanização do material nesse horizonte, confirmando ao fato de estar se aproximando a um horizonte $A$, sendo que seu material apresenta cor mais escura que o horizonte CA (Figura $3 \mathrm{H}$ ). A porosidade não se difere do horizonte CA, sendo predominante planares, seguidamente da cavitária (Figura $3 \mathrm{H}$ ).

Através da análise micromorfológica pode-se dizer que, no geral, o material das matrizes dos níveis pedoestratigráficos coluviais analisados (19Cb, 16Cb, 12Cb, 3Cb, CA e AC) são similares. Pelas características de seus constituintes mátricos, pode-se inferir que 
correspondiam a material fonte de mesma fase pedogenética progressiva (JOHNSON et al., 1990).

Outro aspecto que leva a pensar em mesma fonte pedológica para o material coluvial dos níveis pedoestratigráficos são microfeições que indicam recorrentes ciclos de saturação e dissecação na área fonte. A depleção é um fenômeno efêmero durante as fases de sedimentação dos níveis pedoestratigráficos, e foi mais pronunciada na sequência coluvial superior. Através da pequena pedalidade na sequência coluvial superior sugere retomada da pedogênese progressiva em condições ambientais (climáticas e edáficas) modernas.

\subsection{Mineralogia das Frações Areia, Silte e Argila}

Os principais minerais individualizados nas frações areia, silte e argila, através dos reflexos identificados pelo difratogramas de raio-x obtidos dos horizontes $A C, C A, 3 C b, 6 C b$, $14 \mathrm{Cb}, 16 \mathrm{Cb}, 20 \mathrm{Cb}$ estão expostos nos quadros 1 e 2 . A difração de raio-x das frações areia e silte dos horizonte $A C$ e CA, sequência coluvial superior, revelou os minerais primários apatita, anatásio, feldspatos indiferenciados, feldspato potássico, feldspato sódico ou cálcico, magnetita-magemita, muscovita, plagioclásios e quartzo (Quadro 1). Igualmente registrou os óxidos e hidróxidos de ferro: hematita, lepidocrocita e goethita; bem como os argilominerais caulinita e dickita. Estes último presentes, exclusivamente, na fração silte do horizonte CA. A sequencia coluvial intermadiária, apresenta composição mineralógica nas frações areia e silte similar ao da sequência superior. Registra-se apenas vermiculita desordenada, e em pouca quantidade, na fração silte do horizonte $3 \mathrm{Cb}$.

Analisando tais resultados, os minerais primários são comuns aos derrames vulcânicos ácidos encontrados na porção noroeste do Rio Grande do Sul (PEDRON, 2007). Como na colina fonte dos materiais coluviais que colmataram o paleofundo de vale estudado é mantida por remanescente de riolito hidrotermalizado, pode-se pensar na mistura desses constituintes durante o processo de remoção e sedimentação no fundo de vale. Os óxidos e hidróxidos de ferro (hematita, lepidocrocita e goethita) encontrados, tanto na fração areia quanto na fração silte, podem resultar de remanescentes de alteromorfos (DELVIGNE, 1998), ou do nível hidrotermal, ou concreções ferruginosas geradas pela pedogênese. 
16 | Micromorfologia E Mineralogia De Unidades Pedoestratigráficas Coluviais Em Paleofundo De Vale Na Superfície De São José Dos Ausentes (RS)

De todo modo, destaca-se a presença de minerais primários relativamente resistentes ao intemperismo na fração areia dos níveis pedoestratigráficos, tais como: quartzo, anatásio, muscovita, apatita, magnetita-magemita e feldspato potássico; juntamente com mineral menos resistente ao intemperismo tal como: plagioclásios (SCHAETZL e ANDERSON, 2005).

Quadro 1 - Minerais individualizados através do Difratograma de Raio-X para a fração areia e silte - horizontes AC. ${ }^{1}$ Ângulo de incidência da radiação. ${ }^{2}$ Espaçamento das reflexões (distância entre os planos atômicos dos minerais). * Pico menor, ou pior cristalizado, cujo ângulo de incidência não foi identificado pelo software. - Mineral não identificado. Ap:Apatita. F: Feldspatos indiferenciados. FK:Feldspato potássico. FNa/Ca: Feldspato Sódico ou cálcico. An: Anidrita $\left(\mathrm{CaSO}_{4}\right)$. Ca: caulinita. At:Anatásio $\left(\mathrm{TiO}_{2}\right)$ Qz:Quartzo. M:Magnetita-Magemita. PI:Plagiocásios. Mu:Muscovita $\left[\mathrm{KAl}_{2}\left(\mathrm{AlSi}_{3} \mathrm{O}_{10}\right)(\mathrm{OH})_{2}\right]$. Le:Lepidocrocita (yFeO(OH). Go:Goethita $[\alpha \mathrm{FeO}(\mathrm{OH})]$. He:Hematita $\left(\mathrm{Fe}_{2} \mathrm{O}_{3}\right)$. Da:Dickita $\left[\mathrm{Al}_{2} \mathrm{Si}_{2} \mathrm{O}_{5}(\mathrm{OH})_{4}\right]$. Se:Serpentina $\left(\mathrm{Mg}_{3} \mathrm{Si}_{2} \mathrm{O}_{5}(\mathrm{OH})_{4}\right.$.

\begin{tabular}{|c|c|c|c|c|c|}
\hline Pico & \multicolumn{2}{|c|}{ Areia } & \multicolumn{2}{c|}{ Silte } & Minerais \\
\hline & $2 \Theta^{1}$ & $\AA^{2}$ & $2 \Theta$ & $\AA$ & \\
\hline $\mathrm{a}$ & 14,17 & 6,24 & 14,39 & 6,15 & $\mathrm{Le}$ \\
\hline $\mathrm{b}$ & - & - & 23,08 & 3,85 & $\mathrm{~F}$ \\
\hline $\mathrm{c}$ & 24,31 & 3,66 & 24,22 & 3,67 & $\mathrm{FNa} / \mathrm{Ca}$ \\
\hline $\mathrm{d}$ & - & - & 25,46 & 3,49 & $\mathrm{Qz}$ \\
\hline $\mathrm{e}$ & - & - & 28,00 & 3,18 & $\mathrm{FNa} / \mathrm{Ca}$ \\
\hline $\mathrm{f}$ & - & - & 29,38 & 3,04 & $\mathrm{~F}$ \\
\hline $\mathrm{g}$ & 31,24 & 2,86 & 30,98 & 2,88 & $\mathrm{FK}$ \\
\hline $\mathrm{h}$ & - & - & - & - & $\mathrm{Ca} / \mathrm{Da}$ \\
\hline $\mathrm{i}$ & - & - & - & - & $\mathrm{Go}$ \\
\hline $\mathrm{j}$ & 42,90 & 2,10 & 42,64 & 2,12 & $\mathrm{M}$ \\
\hline $\mathrm{k}$ & - & - & - & - & $\mathrm{Mu}$ \\
\hline $\mathrm{I}$ & 46,30 & 1,96 & 46,12 & 1,96 & $\mathrm{Ap} / \mathrm{Da}$ \\
\hline $\mathrm{m}$ & 47,29 & 1,92 & 47,08 & 1,92 & $\mathrm{Le}$ \\
\hline $\mathrm{n}$ & 49,86 & 1,82 & 49,68 & 1,83 & $\mathrm{Qz}$ \\
\hline $\mathrm{o}$ & 52,35 & 1,74 & - & - & $\mathrm{Le}$ \\
\hline $\mathrm{p}$ & 53,88 & 1,70 & 53,66 & 1,70 & $\mathrm{At}$ \\
\hline $\mathrm{q}$ & 59,16 & 1,56 & 58,91 & 1,56 & $\mathrm{Qz}$ \\
\hline $\mathrm{r}$ & 64,88 & 1,43 & 64,66 & 1,44 & $\mathrm{He}$ \\
\hline
\end{tabular}

Fonte: Organização dos autores. 
No que se refere à fração argila, tomando por base o difratograma de raio-x do horizonte $A C$, com amostra natural, revelou os picos "a", "c" e "f" que expressam a recorrência da difração de uma partícula grande e bem cristalizada (Quadro 2). Com tratamentos de $\mathrm{Mg}, \mathrm{Mg}+\mathrm{Gl}$ e K registra-se pouca variação no pico, contração e expansão parcial, havendo contração/colapso parcial com saturação de $\mathrm{K}$ e aquecimento à $550^{\circ} \mathrm{C}$ (pico "b"). Tal comportamento da difração de raio-x sugere maior estabilidade no mineral e expressa a presença de intercalação de polímeros hidróxi-Al nas entrecamadas (KÄMPF e KLAMT, 1978; TESKE et al., 2013). Assim, o pico "a" foi interpretado como EHE (esmectita com hidróxi entrecamadas - AZEVEDO et al., 2012). O hidróxi-Al entrecamadas pode estar promovendo uma recorrência do reflexo do mineral quase regular $(d, d / 2, d / 3,-$ RESENDE et al., 2005), como se observa pelos picos " $c$ " e " $f$ " (Quadro 2). Caso fosse interestratificações de ilita-vermiculita (I-V) ou vermiculita-ilita (V-I) poderia apresentar espaçamento entre 11 e $13 \AA$, bem como registraria contração a $10 \AA$, em $350^{\circ} \mathrm{C}$, e manutenção de $14 \AA$ com tratamentos de $\mathrm{K}$ e Mg (MAFRA et al., 2002). Pelo fato dos difratogramas não registrarem picos entre 4,8 e 4,3 $\AA$, entende-se que há ausência de gibbsita (INDA et al., 2010; TESKE et al., 2013).

Quadro 2 - Minerais individualizados através do Difratograma de Raio-X para a fração argila - horizonte CA. ${ }^{1}$ Pico de uma partícula grande e bem cristalizada com largura do pico à meia altura (RESENDE et al., 2005). ${ }^{2}$ Ângulo de incidência da radiação. ${ }^{3}$ Espaçamento das reflexões (distância entre os planos atômicos dos minerais). Pico menor, ou pior cristalizado, cujo ângulo de incidência não foi identificado pelo software. - Mineral não identificado. EHE: Esmectita com Hidróxi Entrecamadas. Ca:Caulinita. Cl: Clorita. Vm:Vermiculita.Go: Goethita. Tr: Trimidita $\left(\mathrm{SiO}_{2}\right)$. FK: Feldspato potássico.

\begin{tabular}{|c|c|c|c|c|c|c|c|c|c|c|c|c|c|c|}
\hline Pico & \multicolumn{10}{|c|}{ Tratamentos } & \multicolumn{2}{c|}{ Minerais } \\
\hline & Natural & \multicolumn{2}{|c|}{$\mathrm{Mg}$} & \multicolumn{2}{c|}{$\mathrm{Mg}+\mathrm{Gl}$} & \multicolumn{2}{c|}{$\mathrm{K}$} & \multicolumn{2}{c|}{$\mathrm{K}+350$} & \multicolumn{2}{c|}{$\mathrm{K}+550$} & \\
\hline & $2 \Theta^{2}$ & $\AA^{3}$ & $2 \Theta$ & $\AA$ & $2 \Theta$ & $\AA$ & $2 \Theta$ & $\AA$ & $2 \Theta$ & $\AA$ & $2 \Theta$ & $\AA$ & \\
\hline $\mathrm{a}^{1}$ & 7,09 & 12,46 & 6,98 & 12,65 & 7,08 & 12,47 & 7,16 & 12,33 & 7,01 & 12,6 & $*$ & - & $\mathrm{EHE}$ \\
\hline $\mathrm{b}$ & $*$ & - & $*$ & - & $*$ & - & $*$ & - & $*$ & - & 10,13 & 8,72 & $\mathrm{EHE}$ \\
\hline $\mathrm{c}^{1}$ & 14,34 & 6,17 & 14,06 & 6,29 & 14,26 & 6,20 & 14,29 & 6,19 & 14,16 & 6,25 & $*$ & - & $\mathrm{EHE}$ \\
\hline \hline
\end{tabular}


18 | Micromorfologia E Mineralogia De Unidades Pedoestratigráficas Coluviais Em Paleofundo De Vale Na Superfície De São José Dos Ausentes (RS)

\begin{tabular}{|c|c|c|c|c|c|c|c|c|c|c|c|c|c|}
\hline$d$ & 21,48 & 4,13 & 21,36 & 4,15 & 21,21 & 4,18 & 21,56 & 4,12 & 23,01 & 3,86 & $*$ & - & Go \\
\hline$e$ & 23,21 & 3,83 & 23,16 & 3,84 & 23,14 & 3,84 & 23,14 & 3,84 & 23,01 & 3,86 & $*$ & - & $\mathrm{Tr}$ \\
\hline $\mathrm{f}$ & 24,86 & 3,58 & $*$ & - & $*$ & - & $*$ & - & - & - & $*$ & - & $\mathrm{Ca} / \mathrm{Cl} / \mathrm{Vm}$ \\
\hline $\mathrm{g}^{1}$ & 28,89 & 3,08 & 28,86 & 3,09 & 28,88 & 3,09 & 28,92 & 3,08 & 28,81 & 3,09 & $*$ & - & $\mathrm{EHE}$ \\
\hline $\mathrm{h}^{1}$ & 30,99 & 2,88 & 30,90 & 2,89 & 30,95 & 2,88 & 30,97 & 2,88 & 30,81 & 2,90 & 31,02 & 2,88 & $\mathrm{FK}$ \\
\hline $\mathrm{i}$ & 44,13 & 2,05 & $*$ & - & 44,01 & 2,05 & 44,00 & 2,05 & 43,95 & 2,05 & $*$ & - & $\mathrm{Cl}$ \\
\hline
\end{tabular}

Fonte: Organização dos autores.

De fato, os argilominerais 2:1 com hidróxi-Al entrecamadas assumem característica antigibbsídico pois fixam o $\mathrm{Al}$ entre as camadas, inibindo a formação do $\mathrm{Al}(\mathrm{OH})_{3}$ livre (KER e RESENDE, 1990). Registra-se com baixa cristalidade goethita (pico "d"), caulinita ("e") e clorita ("h") (Quadro 1). A caulinita com alta cristalidade geralmente ocorre no espaçamento de $142 \ominus$ e reflexão de 7,2 a 7,1 $\AA$ (KER e RESENDE, 1990; INDA et al., 2010; PEDRON et al, 2012; TESKE et al., 2013). Sua ausência nesses intervalos, e ocorrência apenas na amostra de argila natural entre a 3,58 $\AA$, aponta para sua maior desordem e menor quantidade (PEDRON et al., 2012). Entre os minerais primários tem-se feldspato potássico como indica os picos bem cristalizados no espaçamento de 2,88 a 2,89 $\AA$ (pico " $\mathrm{g}$ "), obtidos nas amostras de argila natural até o tratamento com $\mathrm{K}+$ aquecimento a $550^{\circ} \mathrm{C}$.

Uma composição similar é encontrada no horizonte CA, porém registra-se trimidita (óxido de silício) e indistintamente caulinita, clorita e vermiculita, com baixa cristalidade,). É possível que esse pico represente a caulinita parcialmente cloritizada (KÄMPF e KLAMT, 1978), sendo que foi previamente identificada no horizonte AC com 3,57 A. Assim, os minerais constituintes da fração argila dos níveis pedoestratigráficos da sequência coluvial superior (horizontes AC e CA) apresentam entre si elevado grau de similaridade, com destaque para EHE como predominante na fração argila.

Em relação a sequência coluvial intermediária, embora a mesma não se mostre melanizada, revelou que o horizonte $3 \mathrm{Cb}$ também apresenta $\mathrm{EHE}$ e respectivas recorrências do mineral com reflexos quase regulares. Baixos reflexos sugerem ocorrência de goethita, trimidita e clorita. Nesse nível pedoestratigráfico também é encontrado feldspato potássico. Essa constituição mineralógica é comum aos horizontes $6 \mathrm{Cb}$ e $14 \mathrm{Cb}$, representativos do centro e base da sequência coluvial intermediária. Percebe-se, até aqui, que não há 
significativas diferenças na mineralogia da fração argila entre as sequências coluviais intermediária e superior, mesmo esta última se mostrando melanizada.

A sequência coluvial inferior, representada pelos níveis pedoestratigráficos $16 \mathrm{Cb}$ e 20Cb, apresentam constituintes na fração argila similares aos das sequências coluviais superior e intermediária. Nesses níveis pedoestratigráficos registra-se a clorita como principal argiomineral, embora ela esteja desordenada e com baixa ocorrência.

Enfim, analisando os resultados do DRX da fração argila constata-se que EHE é dominante $\mathrm{m}$ todos os níveis pedoeestratigráficos da sequência coluvial. Tal argilomineral 2:1 com hidróxi-entrecamadas $(2: 1 \mathrm{HE})$ apresenta maior estabilidade pedogeoquímica (KÄMPF e KLAMT, 1978), relativamente maior que da caulinita, tendo sido gerado no material fonte e permanecido "inalterado" após sua remoção e sedimentação no fundo de vale.

Na literatura ainda há dificuldades em definir os fatores ambientais que levam a formação do 2:1HE (ALMEIDA et al., 2000), por outro lado, acredita-se que são indícios de solos poligenéticos (KÄMPF e KLAMT, 1978; INDA et al., 2010). Contudo, é um processo que pode iniciar ainda na fase de desenvolvimento do saprolito (alteroplasmação) e que pode se manter com o estabelecimento do solo (pedoplasmação), haja vista que os argilominerais 2:1 são formados no estágio de intemperismo da rocha.

No caso das efusivas ácidas do sul do Brasil argilominerais 1:1,como gibbsita e caulinita, estão presentes desde a fase de alteroplasmação (CLEMENTE e AZEVEDO, 2007). Igualmente, são reconhecidos argilominerais 2:1HE e 1:1, como caulinita cristalizada, e com quantidade significativa, horizonte A de Neossolo na mesma superfície geomorfológica da área (PEDRON et al., 2012). Na área de estudo não se percebe essa tendência, registrandose 2:1HE e uma inexpressiva presença de caulinita desordenada. Isso leva a pensar que o material da área fonte gerou 2:1HE desde a fase de alteroplasmação, e constituía um solo jovem (CURI et al., 1984), possivelmente da categoria dos Cambissolos. De fato, a presença de clorita desestruturada, e em baixa quantidade, encontrada nos níveis pedoestratigráfico é indício de alteroplasmação.

A presença de goethita e lepdocrocita nas frações areia e silte dos níveis pedoestratigráfico, sobretudo da goethita com baixa cristalidade, e quantidade, nas frações 
argila, pode indicar as condições ambientais à época de formação do material da área fonte. Esses hidróxidos, sobretudo a goethita, sugerem que havia boa distribuição de chuvas, pequena evapotranspiração, baixas temperaturas, teores elevados de matéria orgânica, meio ácido e restrição de drenagem (KER e RESENDE, 1990). Trata-se de condições ambientais próximas das condições modernas, estabelecidas nos últimos 1.500 anos (BEHLING et al., 2004). De fato, em relação à umidade, a ausência de ferrihidrita aponta para condições hídricas relativamente úmidas na área fonte (KÄMPF e SCHWERTMANN, 1983) e recorrentes após a sedimentação do material no fundo de vale.

\section{CONSIDERAÇÕES FINAIS}

A aplicação da descrição micromorfológica e a determinação mineralógica das frações argila silte e areia dos materiais encontrados em unidades pedoestratigráfica coluviais de paleofundo de vale de segunda ordem colmatado, possibilitou tecer considerações a respeito da área fonte, do grau de retrabalhamento do material e do estágio de evolução intempérica dos mesmos, contribuindo assim para o entendimento relacionado à dinâmica genética e evolutiva dos materiais.

Através da análise micomorfológica observou-se similaridade entre os horizontes coluviais, sugerindo assim, se tratarem de materiais oriundos na mesma fonte e fase pedogenética. Conclui-se que o processo de sedimentação coluvial misturou níveis pedológicos da área fonte com diferentes graus de pedogênese/intemperismo, data a presença de fragmentos líticos e nodulações, dentre outras microfeições. Ao analisar as microfeições foi possível indicar recorrentes ciclos de saturação e dissecação na área fonte, sendo esses um sinal paleoambiental, pois indica regime climático com estações bem definidas. Os processos deposicionais não foram totalmente esclarecidos, possivelmente pela interferência da deformação pós-deposicional, com destaque para a compactação que é responsável pela sutura (coalescência) de agregados. A multiplicidade de agregados diferenciáveis tanto pela cor quanto pela organização de sua micromassa, dispostos com 
distribuição relativa porfírica, sugere que eles possam ter sido depositados tanto por escoamento superficial com alta densidade de sedimentos quanto por fluxos de lama rasos ou por ambos.

A descrição mineralógica das frações areia, silte e argila mostraram que há a presença de minerais primários relativamente resistentes ao intemperismo, juntamente com minerais menos resistentes ao intemperismo, sugerindo assim como hipótese duas situações da dinâmica entre pedogênese e morfogênese na área fonte dos sedimentos: o material fonte deriva de solo pouco evoluído do ponto de vista pedogeoquímico, ou houve contínua remoção até os níveis do saprolito, ou ambas as situações.

Constatou-se também que a Esmectita com Hidróxi Entrecamadas (EHE) é dominante em nos níveis pedoestratigráficos da sequência coluvial. Por este argilomineral sugerir uma maior estabilidade pedogeoquímica, conclui-se que tenha sido gerado no material fonte dos sedimentos entrados no paleofundo de vale e permanecido "inalterado" após sua remoção e sedimentação. A presença de goethita e lepdocrocita assim como a ausência de ferrihidrita nas frações areia e silte pode apontar condições ambientais similares das modernas, pois indicam que havia boa distribuição de chuvas, pequena evapotranspiração, baixas temperaturas, teores elevados de matéria orgânica, meio ácido e restrição de drenagem

\section{AGRADECIMENTO}

Ao CNPq/Programa de Pós-Graduação em Geografia da Unioeste Francisco Beltrão pela bolsa de mestrado, ao CNPq pelo financiamento da pesquisa (Proc.300902/2015-8) e ao Campus da Unioeste pela disponibilidade de sua infraestrutura de pesquisa.

\section{REFERÊNCIAS}

ALMEIDA, F. F. M. O Planalto basáltico da Bacia do Paraná. Boletim Paulista de Geografia, n. 24, p. 03-34, 1956. 
ALMEIDA, J.A.; MAÇANEIRO, K.C.; KLAMT, E. Mineralogia da fração argila de solos vermelhos com horizontes superficiais brunados do Planalto de Lages (SC). Revista Brasileira de Ciência do Solo. V.24, p.815-828, 2000.

ARAÚJO, A.G.M.; PAISANI,J.C.; SCHARAGE, T.J.; FEATHERS, J.K.; HARTMANN,G.A.; RICCI, O. The "Lagoa do Camargo 1" Paleoindian site: some implications for tropical geomorphology, pedology, and paleoenvironments in southeastern Brazil. Geoarchaeology, 1-16, 2017.

AZEVEDO, A.C.; PEDRON, F.A.; SARTOR, L.R.; CASARINI, P.G. Filossilicatos 2:1 com hidróxi entre camadas em solos: estado atual do conhecimento e das perspectivas de pesquisa. Revista de Ciências Agrárias - Amazonian Journal of Agricultural and Environmental Sciences, v.55, n.3, p.236-243, 2012.

BERTRAN, P.; TEXIER, J.P. Facies ad microfacies of slope deposits. Catena, v.35, p.99- 121, 1999.

BEHLING, H.; PILLAR, V.D.; ORLÓCI, L.; BAUERMANN, S.G. Late Quaternary Araucaria forest, grassland (Campos), fire and climate dynamics, studied by high-resolution pollen, charcoal and multivariate analysis of the Cambará do Sul core in southern Brazil. Palaeogeography, Palaeoclimatology, Palaeoecology, v. 204, 277-297, 2004.

BIFFI, V.H.R.; PAISANI, J.C. Micromorfologia de colúvio-alúvios em paleovoçorocas colmatadas nas superfícies de cimeira de Pinhão/Guarapuava e Palmas/Caçador - Sul do Brasil. Revista Brasileira de Geomorfologia, v.20, n.4, p.735-749. 2019.

CLEMENTE, C.A.; AZEVEDO, A.C. Mineral weatherig in acid saprolites from subtropical, Southern Brazil. Scientia Agricola, Piracicaba (Brazil), v.64, n.6, p.601-607, 2007.

CURI, N.; KÄMPF, N.; RESENDE, N. Mineralogia, química, morfologia e geomorfologia de solos originados de rochas efusivas das encostas superior e inferior do nordeste, no Rio Grande do Sul. Revista Brasileira de Ciência do Solo. V.8, p.269-276, 1984.

DELVIGNE, J.E. 1998 Atlas of micromorphology of mineral alteration and weathering. The Canadian Mineralogist, Special publicantion 3, ORSTOM éditions, 495p.

FEDOROFF, N.; COUTRY-A.A.; GUO, Z. Palaeosoils and relict soils. In: Stoops, G.; Marcelino, V.; Mees, F.(Ed.) Interpretation of micromorphological features of soils and regoliths. Elsevier, p.623-662. 2010.

GUIBAUDO. G. Subaqueous sediment gravity flow deposits: practical criteria for their field description and classification. Sedimentology 39, 423-454, 1992.

IBGE - EMBRAPA. Mapa de solos do Brasil. Rio de Janeiro: IBGE, 2001. Escala 1:5.000.000. 2001.

IBGE. Mapa de Vegetação do Brasil. Rio de Janeiro: IBGE, 2004. Escala 1:5.000.000. 2004.

INDA, A.V.; TORRENT, J.; BARRÓN, V.; BAYER, C. Aluminum hydroy-interlayered minerais and chemical properties of a subtropical Brazilian oxisol under no-tillage and conventional tillage. Revista Brasileira de Ciência do Solo. v.34, p.33-41, 2010. 
JOHNSON, D.L.; KELLER, E.A.; ROCKWELL, T.K. Dynamic pedogenesis: new views on some key soil concepts, and a model for interpreting Quaternary soils. Quaternary Research 33, p.306-319, 1990.

KÄMPF, N.; KLAMT, E. Mineralogia e gênese de Latossolos (Oxisols)e solos podzólicos da região nordeste do Planalto Sul-Riograndense. Revista Brasileira de Ciência do Solo. V.2, p.68-73, 1978.

KÄMPF, N.; SCHWERTMANN, U. Goethite and hematite in a climosequence in Southern Brazil and their application in classification of kaolinitic soils. Geoderma, v.29, p.27-39, 1983.

KER, J.C.; RESENDE, M. Caracterização química e mineralógica de solos brunos subtropicais do Brasil. Revista Brasileira de Ciência do Solo. V.14, p.215-225, 1990.

LINDBO, D.; L., SCOLT, M. H.; VEPRASKAS, M. J. Redoximorphic Features. In: STOOPS, G.; MARCELINO, V.; MEES, F. (Eds.). Interpretation of micromorphological features of soils and regoliths. Amsterdam: Elsevier, p. 129-147, 2010.

MAFRA, A.L.; MIKLÓS, A.A.W.; VOLKOFF, B; MELFI, A.J. Pedogênese numa seqüência latossolo-espodossolo na região do Alto Rio Negro, Amazonas. Revista Brasileira de Ciência do Solo. v.26, p.381-394, 2002.

MÜCHER, H.; VAN STEIJN, H.; KWAAD, F. Colluvial and mass wasting deposits. In: Stoops, G.; Marcelino, V.; Mees, F.(Ed.) Interpretation of micromorphological features of soils and regoliths. Elsevier, p.37-48. 2010.

PAISANI, J.C; PONTELLI, M.E. Grau de evolução da cobertura pedológica de área fonte de depósitos coluviais a partir da análise da mineralogia de argilas - Planalto Basáltico - SW PR. Revista de Geografia, UFPE, V.especial VIII SINAGEO, n.1, 2010.

PAISANI, J. C.; PONTELLI, M. E. Propriedades micromorfológicas de colúvios em encosta no médio vale do Rio Marrecas (SW PR) - bases para distinção de formações superficiais alóctones e autóctones em substrato basáltico. Pesquisas em Geociências, UFRGS, v.39 (1), p.53-62, 2012.

PAISANI, J. C.; PONTELLI, M. E; ANDRES, J. Superfícies aplainadas em zona morfoclimática subtropical úmida no Planalto Basáltico da Bacia do Paraná (SW Paraná/ NW Santa Catarina): primeira aproximação. Geociências, São Paulo, v.27, n.4, p.541-553, 2008.

PAISANI, J.C., PONTELLI, M.E.; CALEGARI, M.R. Contribuição para a reconstrução de perfis de alteração no Planalto de Palmas/Água Doce - Sul do Brasil. GEOgraphia, ano 17, n.34, p.225246, 2015.

PAISANI, J. C.; PONTELLI, M. E; PEREIRA, J. S.; CAVAZINI, A. J. Pedogênese e Morfogênese no Médio Vale do Rio Marrecas durante o Quaternário Tardio - Sul do Brasil. Revista Ra'e Ga - UTFPR - Curitiba, v.41 Temático de Geomorfologia, p.49-64 , Ago/2017.

PEDRON, F.A; AZEVEDO, A. C.; DALMOLIN, R. S. D. Alteração mineralógica de Neossolos em uma climo-litossequência no Planalto do Rio Grande do Sul. Ciência Rural, Santa Maria, v.42, n.3, p.451-458, 2012. 
PEDRON, F.A. Mineralogia, morfologia e classificação de saprolitos e Neossolos derivados de rochas vulcânicas no Rio Grande do Sul. 2007. 160p. Tese (Doutorado). Santa Maria, Universidade Federal de Santa Maria, 2007.

PEREIRA, J. S. Pedogênese e Morfogênese na Superfície de São José dos Ausentes (RS) no Quaternário Tardio: Evidências em Paleofundo de Vale na Bacia Hidrográfica do Rio dos Touros. 2017. 135f. Dissertação (Mestrado em Geografia) - Universidade Estadual do Oeste do Paraná, Francisco Beltrão. 2017.

PEREIRA, J. S.; PAISANI, J. C.; FUGITA, R. H.; PONTELLI, M. E.; HENDGES, E. R. Caracterização preliminar das formações superficiais das superfícies de São José dos Ausentes (RS)/ São Joaquim (SC). In. XI SINAGEO, 2016, Maringá (PR). Anais do XI SINAGEO - Simpósio Nacional de Geomorfologia. Maringá (PR), n. 331, 2016.

RESENDE, M.; CURI, N.; KER, J.C.; REZENDE, S.B. Mineralogia de solos brasileiros: interpretações e aplicações. Editora UFLA, 2005. 187p.

SCHAETZL, R.J.; ANDERSON, S. Soils: Genesis and Geomorphology. Cambridge University Press, Cambridge, UK, 833p. 2005.

SCHERER, C; LORSCHEITTER, M. L. Vegetation dynamics in the southern Brazilian highlands during the last millennia and the role of bogs in Araucaria forest formation. Quaternary International, 325:3-12. doi:10.1016.

SCHLICK, F. E. Alternativas de Manejo Para os Campos de Cima da Serra. 2004. Tese de Doutorado. Faculdade de Agronomia, Programa de Pós-graduação em Zootecnia. Universidade Federal do Rio Grande do Sul, Porto Alegre, 2004.

STOLT, M.; LINDBO, D. L. Soil organic matter. In: STOOPS, G.; MARCELINO, V.; MEES, F. (Eds.). Interpretation of micromorphological features of soils and regoliths. Amsterdam: Elsevier, p. 369-396. 2010.

STOOPS, G. Guidelines for analysis and description of soil and regolith thin sections. Madison, Wisconsin, Soil Science Society of America, 2003,184p.

SUGUIO, K. Geologia do Quaternário e mudanças ambientais. São Paulo: Paulo's Comunicações e. Artes Gráficas, 1999. 362p.

TESKE, R.; ALMEIDA, J.A.; HOFFER, A.; NETO, A.L. Caracterização mineralógica dos solos derivados de rochas efusivas no Planalto Sul de Santa Catarina, Brasil. Revista de Ciências Agroveterinárias, Lages (SC), v.12, n.2, p.187-198, 2013

WILDNER, W; RAMGRAB, G. E; LOPES, L. da C; IGLESIAS C. M. da F. Mapa Geológico do Estado do Rio Grande do Sul. Porto Alegre: CPRM, 2006, Escala: 1:750.000. Programa Geologia do Brasil. Superintendência Regional de Porto Alegre. 